\title{
EFFECT OF SPACING PRESENTATIONS ON RETENTION OF A PAIRED ASSOCIATE OVER SHORT INTERVALS ${ }^{1}$
}

\author{
LLOYD R. PETERSON, RICHARD WAMPLER, MEREDITH KIRKPATRICK, \\ AND DOROTHY SALTZMAN
}

\author{
Indiana University
}

\begin{abstract}
3 experiments varying the interval between 2 presentations of paired associates were reported. Other pairs filled the spacing and retention intervals. Pairs consisting of a word and a number as well as pairs consisting of 2 words showed a superiority at $8 \mathrm{sec}$. and longer retention intervals when presentations were spaced. Increasing the spacing interval beyond $8 \mathrm{sec}$. did not increase recall, when a 2 -sec. rate of presentation was used. A 2 -factor explanation of the findings was suggested, in which cue learning was the major factor influencing recall at longer retention intervals, while a 2 nd factor was confounded with cue learning at short retention intervals.
\end{abstract}

An initial investigation varying the time interval between two presentations of an individual pair of associates has been reported (Peterson, Hillner, \& Saltzman, 1962). Using a technique described earlier (Peterson, Saltzman, Hillner, \& Land, 1962), presentations of other pairs of words and numbers filled both a spacing interval between two presentations and a retention interval from second presentation to test for recall. It was found that the retention curve after a 0-sec. spacing interval was higher at the 2 - and 4 -sec. retention intervals than the retention curve after an 8-sec. spacing interval. However, at the 8 - and 16-sec. retention intervals the superiority was reversed.

If one assumes that the retention curve reflects retained amount of learning in a simple way, then the finding of poorer retention the longer the interval between presentations seems quite reasonable. The retention curve drops off rapidly after one presentation and hence when a second increment to associative strength is given after an interval the summed

1 The research reported was supported by Grant G12917 from the National Science Foundation to Indiana University. effect of the two presentations should be less than in the case where the second increment is added before forgetting of the first learning has occurred. Although such a view is supported by the findings at 2- and 4 -sec. retention intervals, the superiority of the spaced presentations at longer retention intervals stands in direct contradiction to such a view. Why should an arrangement permitting partial forgetting of the first pairing result in improved retention at these longer intervals? Before attempting an explanation it seemed wise to confirm and extend the findings. The studies to be described used the same general method that was used in the earlier studies. The initial study varied length of the spacing interval, while the retention interval was held constant at a value expected to produce superiority for spaced presentations.

\section{Method}

\section{EXPERIMENT I}

Subjects.-Thirty $S_{\mathrm{s}}$ from introductory psychology classes at Indiana University served in fulfillment of a class requirement. Apparatus.-A memory drum was set in a $3 \times 4 \mathrm{ft}$. black screen. A sliding shutter ermitted exposure of any one of multiple 
columns of material typed on tapes up to $3 \mathrm{ft}$. in length.

Procedure.-All $S$ s were tested 12 times in each of six conditions. The time between spacing of two presentations of a pair of associates was either $0,2,4,8,16$, or $32 \mathrm{sec}$. The retention interval following the second presentation was $16 \mathrm{sec}$. in all conditions. Stimulus members of a pair were 3- and 4-letter singlesyllable familiar words. Responses were the numbers $1-15$. The pairs were presented and tested in 12 blocks of exposures. Blocks were from 26 to 34 exposures long. Presentation and test of the six conditions overlapped within a given block. A stimulus word was used only in one test over the experiment, while the same numbers were randomly assigned repeatedly in each succeeding block. A given condition was begun in every serial position within a block and was approximately equally of ten preceded and followed by every other condition in its first presentation. Dummy pairs began each block and filled in where needed within the blocks. Dummy pairs were repeated and tested in a manner that made them indistinguishable from pairs that were scored. The $S$ s were instructed to speak everything that they saw in the drum and give the appropriate number when it was missing. Guessing was encouraged. Six seconds of blank exposures occurred between blocks. The drum turned at a 2 -sec. rate.

\section{Results}

Table 1 indicates that the optimum spacing intervals were 8 and $16 \mathrm{sec}$. An analysis of variance resulted in a significant spacing effect, $F(5,145)$ $=2.44, p<.05$. The 8 - and 16-sec. intervals were significantly different from the 0 -sec. interval at the .05 level, using the Duncan multiple-

TABLE 1

Proportions Correct in Exp. I

\begin{tabular}{c|c|c|c|c|c|c}
\hline & \multicolumn{5}{|c|}{ Spacing Interval (sec.) } \\
\hline & 0 & 2 & 4 & 8 & 16 & 32 \\
\hline $\bar{X}$ & .39 & .43 & .47 & .50 & .51 & .45 \\
\hline$S E$ & .03 & .03 & .06 & .05 & .04 & .04 \\
\hline
\end{tabular}

TABLE 2

Proportions Rlicalled in ExP. II

\begin{tabular}{c|c|c|c|c}
\hline & \multicolumn{3}{|c}{ Retention Interval (sec.) } \\
\cline { 2 - 4 } $\begin{array}{c}\text { Spacing } \\
\text { Interval } \\
\text { (sec.) }\end{array}$ & \multicolumn{2}{|c|}{8} & \multicolumn{2}{|c}{60} \\
\cline { 2 - 4 } & $\bar{X}$ & $S E$ & $\bar{X}$ & $S E$ \\
\hline 0 & .54 & .03 & .33 & .03 \\
8 & .61 & .04 & .43 & .04 \\
60 & .60 & .04 & .43 & .04 \\
\hline
\end{tabular}

range test. Other differences were not significant.

\section{EXPERIMENT II}

\section{Method}

A second experiment was planned to test the spacing intervals extended to lengths approximating the intervals between successive presentations of an item in list learning. At the same time each presentation was made to involve two exposures, as is also the case in paired-associate learning using the anticipation technique. However, the heterogeneity of events accompanying the use of the anticipation technique was considered an unnecessary complication, and both members of a pair were presented together on the first exposure of a presentation, while the stimulus was presented alone on the succeeding turn of the drum. The $S$ was instructed to read aloud everything he saw in the drum aperture and in addition to say the response aloud whenever he saw the stimulus alone. Hence a double exposure was invariably a double pairing. Presentations of this kind had previously been found to be effective (Peterson, Saltzman, Hillner, \& Land, 1962). Two such presentations were given, separated by either 0,8 , or 60 sec., and tested at either an 8 - or 60 -sec. retention interval. Sequences of exposures were organized into 18 blocks from 19 to 34 exposures long. Following every third block was a 10 -sec. rest, and between the remaining blocks there were 8-sec. rests. Stimuli were similar to those in the previous experiment, and the responses were the numbers 1-19. Thirty-six $S$ s from the same source as in Exp. I were tested 18 times in each of six conditions. Other details followed the procedure of Exp. I. 


\section{Results}

Table 2 shows that the superiority of spaced pairings was at least as great at a 60 -sec. retention interval as at $8 \mathrm{sec}$. An analysis of variance showed the spacing factor to be significant at the .01 level, $F(2,70)$ $=5.81$. Retention was also significant, $F(1,35)=48.8$.

\section{EXPERIMENT III \\ Method}

The experiments described previously used numbers as responses, and these were repeatedly assigned to different words over the course of the experiment. Experiment III used words as responses which were used only once, with another word as stimulus. The words were all single-syllable familiar words. There were three presentation conditions: a single presentation, two presentations with no intervening exposures, and two presentations with four intervening exposures on the drum. Test for retention was given either after one other exposure or four other exposures. Twelve $S$ s were tested at a 2 -sec. rate, and 12 other $S$ s were tested at a $4-\mathrm{sec}$. rate. A given $S$ was tested 32 times in each of six conditions. The 32 blocks were from 29 to 38 exposures in length. Eight seconds of blank exposures separated blocks, save for three changes of tape which lasted approximately $30 \mathrm{sec}$. each. Although both experiments were run in the same week by the same $E$, one was run before the other, and assignment of $S \mathrm{~s}$ to the two different rates of presentation was not random.

TABLE 3

Proportion of Correct Recalls in EXP. III

\begin{tabular}{|c|c|c|c|}
\hline Retention Interval & $\begin{array}{l}\text { One } \\
\text { Presen- } \\
\text { tation }\end{array}$ & \begin{tabular}{|l|} 
Two \\
Massed \\
Presen- \\
tations
\end{tabular} & $\begin{array}{l}\text { Two } \\
\text { Spaced } \\
\text { Presen- } \\
\text { tations }\end{array}$ \\
\hline $\begin{array}{l}\text { 2-sec. presentation rate } \\
2 \mathrm{sec} \text {. } \\
8 \mathrm{sec} \text {. }\end{array}$ & $\begin{array}{l}.79 \\
.14\end{array}$ & $\begin{array}{l}.87 \\
.26\end{array}$ & $\begin{array}{l}.79 \\
.29\end{array}$ \\
\hline $\begin{array}{l}\text { 4-sec, presentation rate } \\
4 \text { sec. } \\
16 \text { sec. }\end{array}$ & $\begin{array}{l}.67 \\
.23\end{array}$ & $\begin{array}{l}.78 \\
.26\end{array}$ & $\begin{array}{l}.75 \\
.45\end{array}$ \\
\hline
\end{tabular}

TABLE 4

Analyses of Variance of Proportions CORRECT: EXP. III

\begin{tabular}{|c|c|c|c|c|c|}
\hline \multirow{3}{*}{ Source } & \multirow{3}{*}{$d f$} & \multicolumn{4}{|c|}{ Presentation Rate } \\
\hline & & \multicolumn{2}{|c|}{2 sec. } & \multicolumn{2}{|c|}{4 sec. } \\
\hline & & $M S$ & $F$ & $M S$ & $F$ \\
\hline $\begin{array}{l}\text { Presentation (P) } \\
\text { Retention (R) } \\
S \mathrm{~s} \\
\mathrm{P} \times \mathrm{R} \\
\mathrm{P} \times S \mathrm{~s} \\
\mathrm{R} \times S \mathrm{~s} \\
\mathrm{P} \times \mathrm{R} \times S \mathrm{~s}\end{array}$ & \begin{tabular}{r|}
2 \\
1 \\
11 \\
2 \\
22 \\
11 \\
22
\end{tabular} & $\begin{array}{l}.061 \\
6.216 \\
.022 \\
.044 \\
.006 \\
.020 \\
.006\end{array}$ & $\begin{array}{r}10.1 * * * \\
310.8 * * \\
7.3 * * \\
3.3 * *\end{array}$ & $\begin{array}{r}.133 \\
3.138 \\
.111 \\
.073 \\
.010 \\
.037 \\
.010\end{array}$ & $\begin{array}{r}13.3^{* * *} \\
84.8^{* * *} \\
7.3^{* * *} \\
3.7 * *\end{array}$ \\
\hline
\end{tabular}

$* * p<.01$.

\section{Results}

The mean proportions correct are shown in Table 3 . The 2 -sec. rate conditions will be considered first. It is apparent that two presentations were not better than one unless they were massed. The interaction between spacing interval and retention interval found in the earlier study (Peterson, Hillner, \& Saltzman, 1962) was again present. At the 8 -sec. retention interval a slight superiority for the spaced condition over the massed condition appeared. Both double presentation conditions were notably superior to a single presentation at the 8 -sec. retention interval. An analysis of variance of the proportions correct is shown in Table 4. Both main effects as well as the interaction were significant at the .01 level.

Looking next at the 4 -sec, rate, the interaction between spacing interval and retention interval was again evident (Table 3 ). The analysis of variance (Table 4) again showed significant main effects as well as a significant interaction.

Comparison of the 2-sec, rate with the 4 -sec. rate should be made with caution, since $S$ s were not randomized between the two groups. However, the differences are suggestive and 
relevant to the problem of the nature of short-term forgetting. Note that for the conditions where one competing presentation intervened before final presentation and test, retention dropped off in all three comparisons when the interval was lengthened to 4 sec. This occurred in spite of the longer time that the tested pair was exposed in the 4 -sec. conditions. On the other hand for those single and spaced conditions where four other pairs intervened before the test, retention increased markedly when exposure time and retention interval became longer. It would seem that length of the retention interval was an important factor at the shorter intervals, while duration of the original pairing was the dominant factor at the longer intervals. It may be that events other than the interfering pairs presented in the drum are productive of forgetting for a brief time after presentation.

\section{Discussion}

The experiments described in this paper together with the previous study (Peterson, Hillner, \& Saltzman, 1962) indicate that a short-term retention curve does not reflect associative learning in any simple manner. It would seem necessary to postulate at least two factors to account for short-term associative retention. It may plausibly be assumed that what is being tested at intervals of $6 \mathrm{sec}$. and longer is the association between members of a pair, or cue learning. This is characterized by relatively slow retention loss and is what is ordinarily understood by the term learning. Spacing of presentations increases the effectiveness of this aspect of retention. The explanation for the superiority of spacing is not apparent. It is possible that attentional considerations are involved. Even though $S$ pays attention to the degree that he is able to speak correctly what he sees on the second of two successive identical presentations, less activity on his part may result than would be the case if the presentation had not just occurred. To what extent such an explanation can be investigated experimentally remains to be seen.

It seems likely that the cue learning just mentioned is confounded at very brief retention intervals by another factor. This aspect of recall is subject to quite rapid forgetting and the decrement after spaced presentations at the shorter retention intervals would then reflect this factor. A more detailed specification of this factor awaits further research but it may be a kind of response bias or availability, or what the senior author has described as background conditioning (Peterson, 1963).

\section{REFERENCES}

Peterson, L. R. Immediate memory: Data and theory. In C. N. Cofer \& B. S. Musgrave (Eds.), Verbal behavior and learning: Problems and processes. New York: McGraw-Hill, 1963.

Peterson, L. R., Hillner, K., \& Saltzman, D. Supplementary report: Time between pairings and short-term retention. $J$, exp. Psychol., 1962, 64, 550-551.

Peter.son, L. R., Saltzman, D., Hilluner K., \& LAND, V. Recency and frequency in paired-associate learning. $J$. exp. Psychol., 1962, 63, 396-403.

(Received September 10, 1962) 